\title{
Family Study
}

National Cancer Institute

\section{Source}

National Cancer Institute. Family Study. NCI Thesaurus. Code C15407.

Research conducted on related or non-related members of families, examining the affects of genetics, the environment, or twin offspring. 